\title{
norden
}

\section{Nordic textile reuse and recycling}

Increased collection, sorting, reuse and recycling of used textiles in the Nordic region

Summary and recommendations

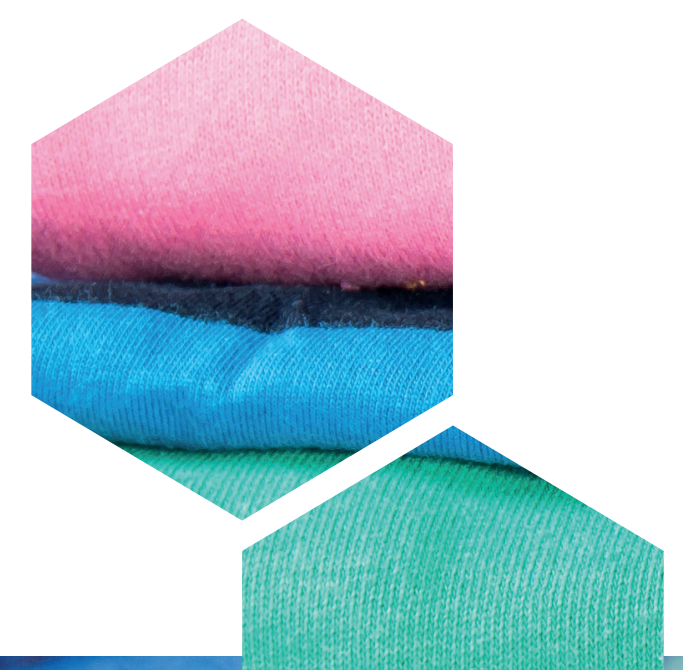

/Policy brief 
Nordic textile reuse and recycling

Increased collection, sorting, reuse and recycling of used

textiles in the Nordic region

ISBN 978-92-893-3956-8 (PRINT)

ISBN 978-92-893-3957-5 (PDF)

http://dx.doi.org/10.6027/ANP2015-714

ANP 2015:714

(C) Nordic Council of Ministers, 2015

Authors: David Palm, IVL Swedish Environmental Research Institute, Nikola Kiørboe, Copenhagen Resource Institute, Maria Elander, IVL Swedish Environmental Research Institute Editors: Sanna Due-Sjöström, Naturvardsverket,

Páll Tómas Finnsson

Layout: Gitte Wejnold

Photos: SignElements

Font: Meta LF

Paper: Munken Polar

Copies: 40

Print: Rosendahls-Schultz Grafisk

www.norden.org/en/publications

\section{Nordic co-operation}

Nordic co-operation is one of the world's most extensive forms of regional collaboration, involving Denmark, Finland, Iceland, Norway, Sweden, and the Faroe Islands, Greenland, and Åland.

Nordic co-operation has firm traditions in politics, the economy, and culture. It plays an important role in European and international collaboration, and aims at creating a strong Nordic community in a strong Europe.

Nordic co-operation seeks to safeguard Nordic and regional interests and principles in the global community. Common Nordic values help the region solidify its position as one of the world's most innovative and competitive.

\section{Nordic Council of Ministers}

Ved Stranden 18

DK-1061 Copenhagen $\mathrm{K}$

Telefon (+45) 33960200

www.norden.org 


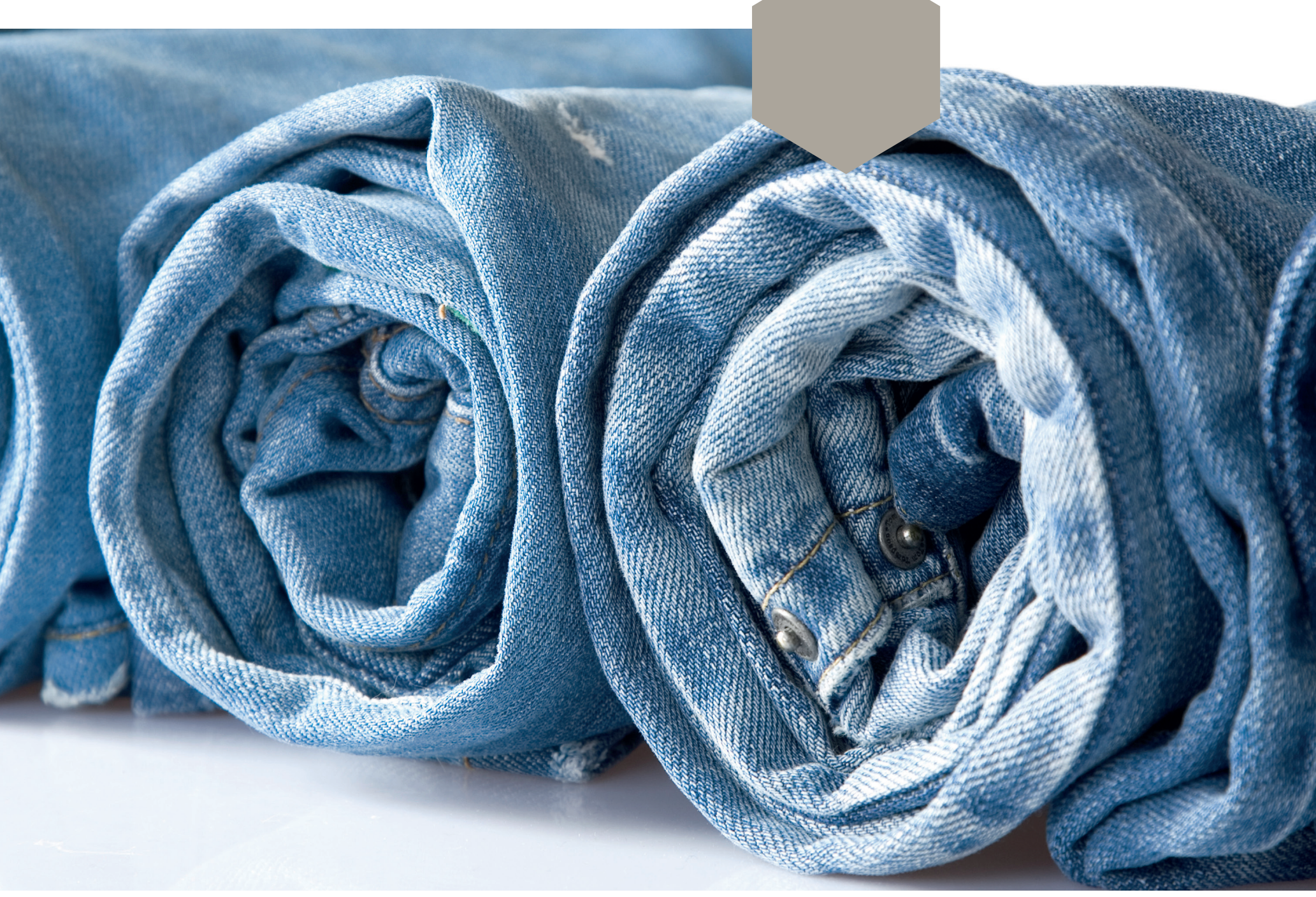




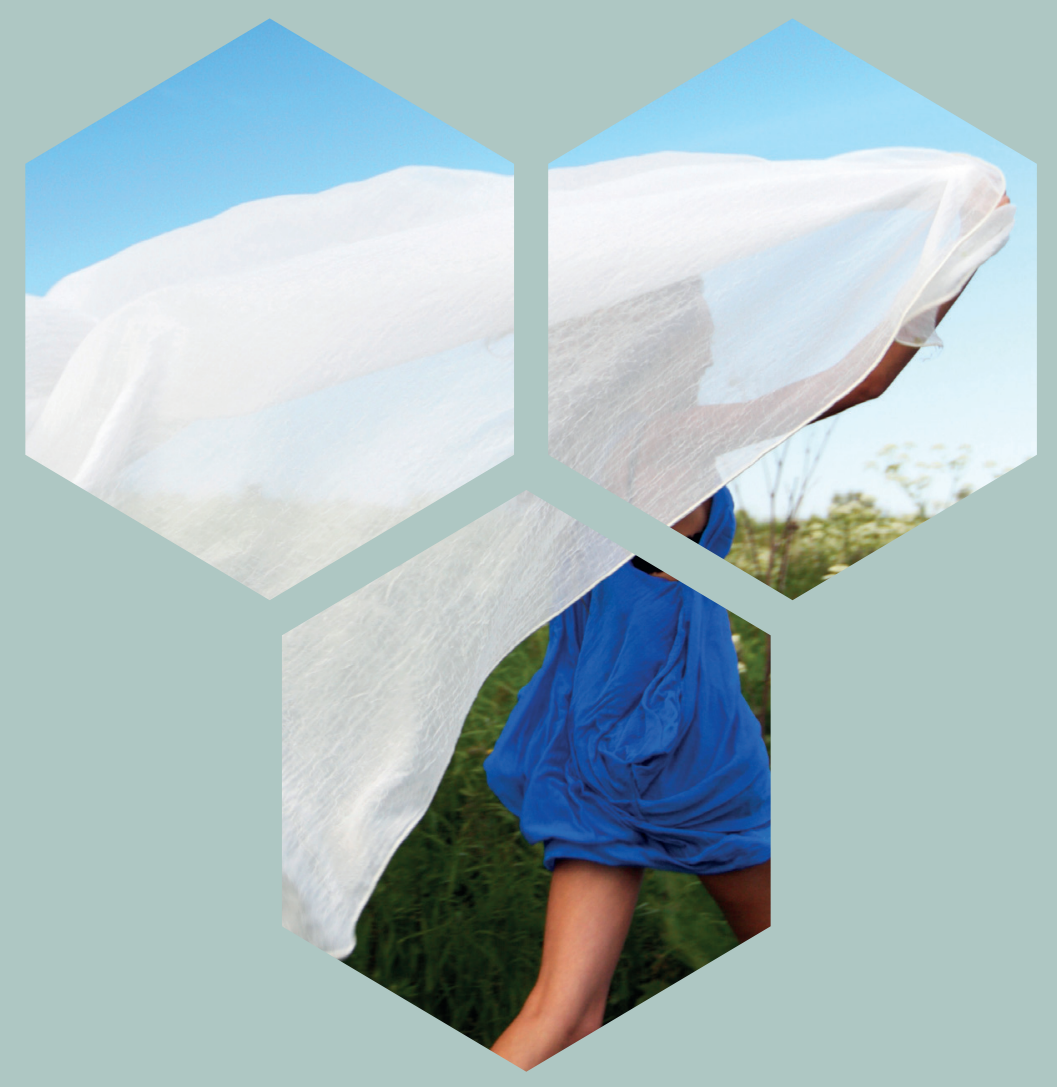




\section{Nordic textile reuse and recycling}

Increased collection, sorting, reuse and recycling of used textiles in the Nordic region

Summary and recommendations

Policy brief

David Palm, IVL Swedish Environmental Research Institute David Watson, Copenhagen Resource Institute Nikola Kiørboe, Copenhagen Resource Institute Maria Elander, IVL Swedish Environmental Research Institute 

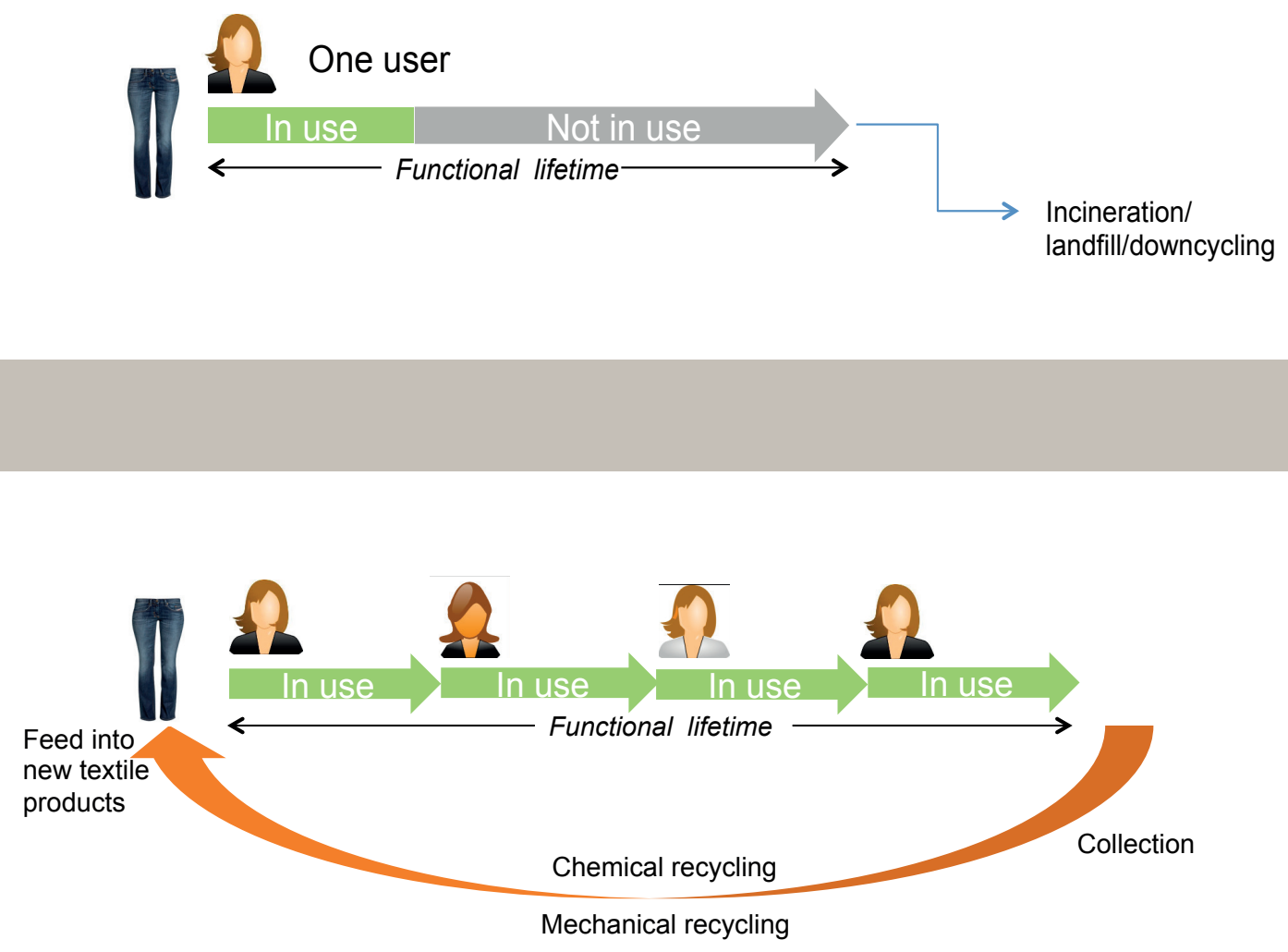

David Watson, 2014 


\section{Vision for the Nordic textile sector}

Every year 350,000 tonnes of textiles are consumed in the Nordic region, of which only 120,000 tonnes of used textiles are separately collected. This corresponds to about one third of all new textiles put on the market. Every kilogram of textiles produced on average corresponds to the emission of 15 kilograms of carbon dioxide.

In the current paradigm most textiles are used only for part of their functional lifetime and then sent to incineration and landfill with a waste of high grade resources. The three projects The Nordic textile reuse and recycling commitment, A Nordic strategy for increased reuse and recycling of textiles as well as An extended producer responsibility (EPR) system and new business models to increase reuse and recycling of textiles in the Nordic region have all aimed for a joint vision for textiles. The vision includes multiple uses during the textile products' entire functional lifetime, whether at one or several owners. Further, it aims for legitimate collection for both reuse and, where reuse is not possible, for high grade recycling into new textile products.

Via sustainable management of textiles, the vision is to create a competitive advantage, green jobs and environmental benefits in the Nordic region.

The three textile reuse and recycling projects are part of the Nordic Prime Ministers' initiative, The Nordic Region, leading in green growth. 


\section{Opportunities and recommendations}

\author{
To seize the opportunities for \\ increased competitiveness for a \\ more sustainable textile sector \\ in the Nordic region there has to \\ be a common goal. Nordic policy \\ makers are called to:
}

- Define ambitious and clear binding targets for collection, sorting, reuse and recycling of used textiles. The targets should include minimum targets on Nordic levels, allowing for more ambitious national targets. Each target should be accompanied by interim targets, enabling assessment and prognosis of target achievement.

- Introduce policy measures securing target achievement for the defined targets for collection, sorting, reuse and recycling of used textiles. Some policy measures can be coordinated at the Nordic level.
To ensure legitimate and wellfunctioning collection and management of used textiles, Nordic policy makers are called to:

\section{- Endorse the future development} and mandatory use of only certified actors involved in collection, sorting, selling for reuse and recycling of used textiles in accordance with The Nordic textile reuse and recycling commitment.

- Further investigate, develop and possibly also initiate pilot tests of promising models of either voluntary or mandatory EPR systems.

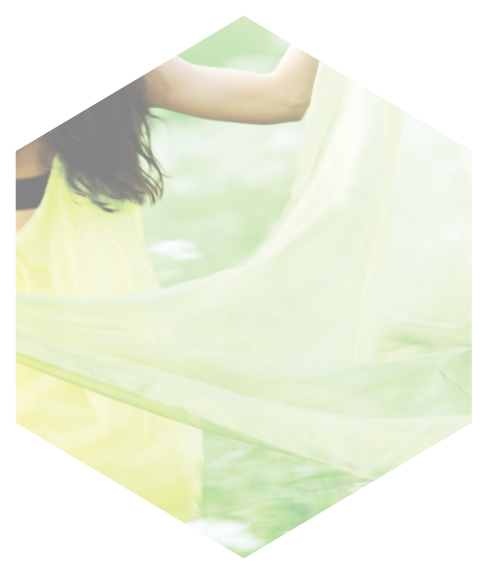

To support green job creation within the Nordic region and support local businesses, Nordic policy makers are called to:

\section{- Evaluate and support business} models in the field of collective use, reuse and prolonged (active) lifetime of textiles.

- Encourage design for durability and higher quality via policy measures.

- Raise awareness of alternative business models amongst both consumers and producers in order to support their spread and acceptance. 

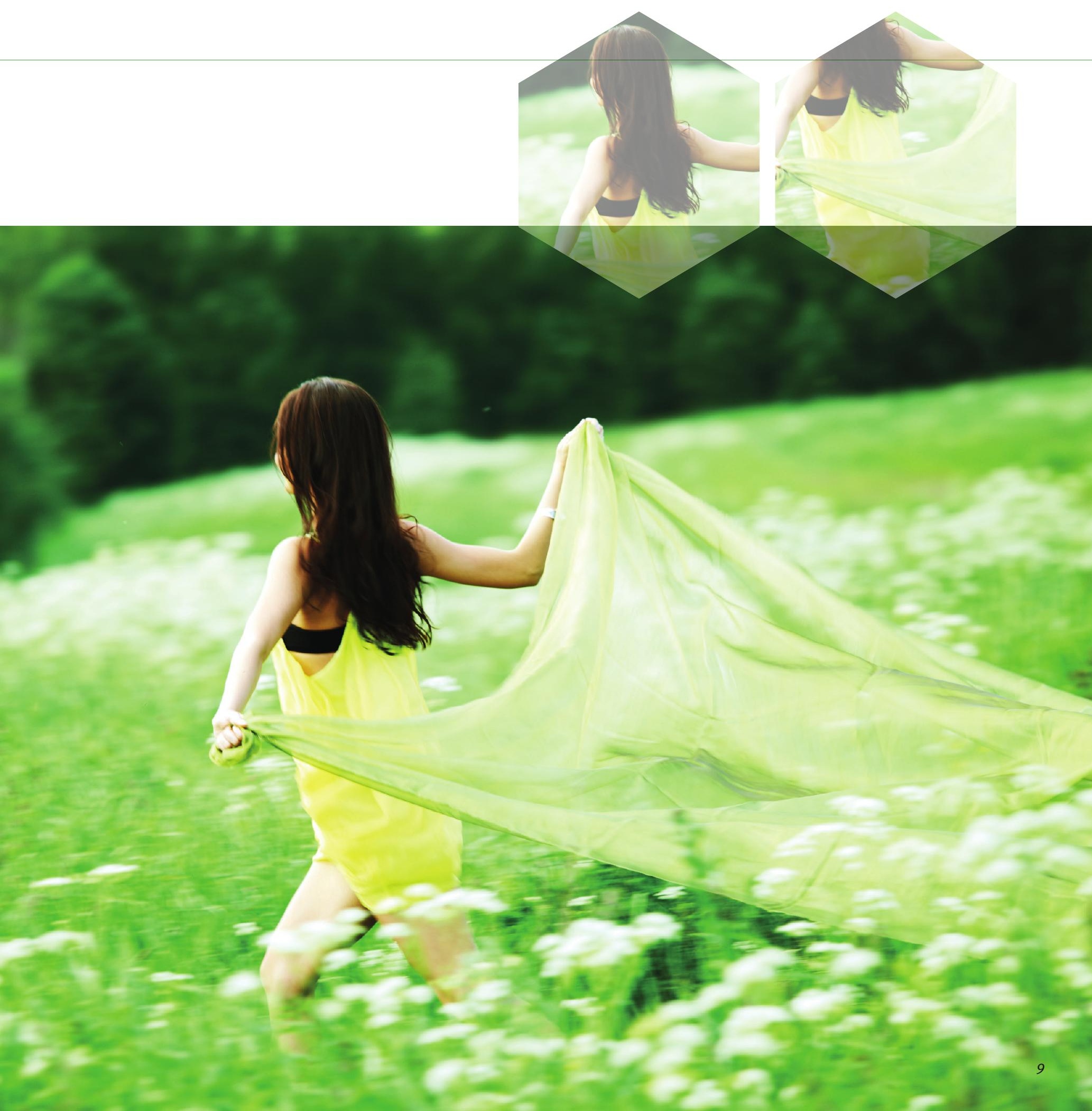


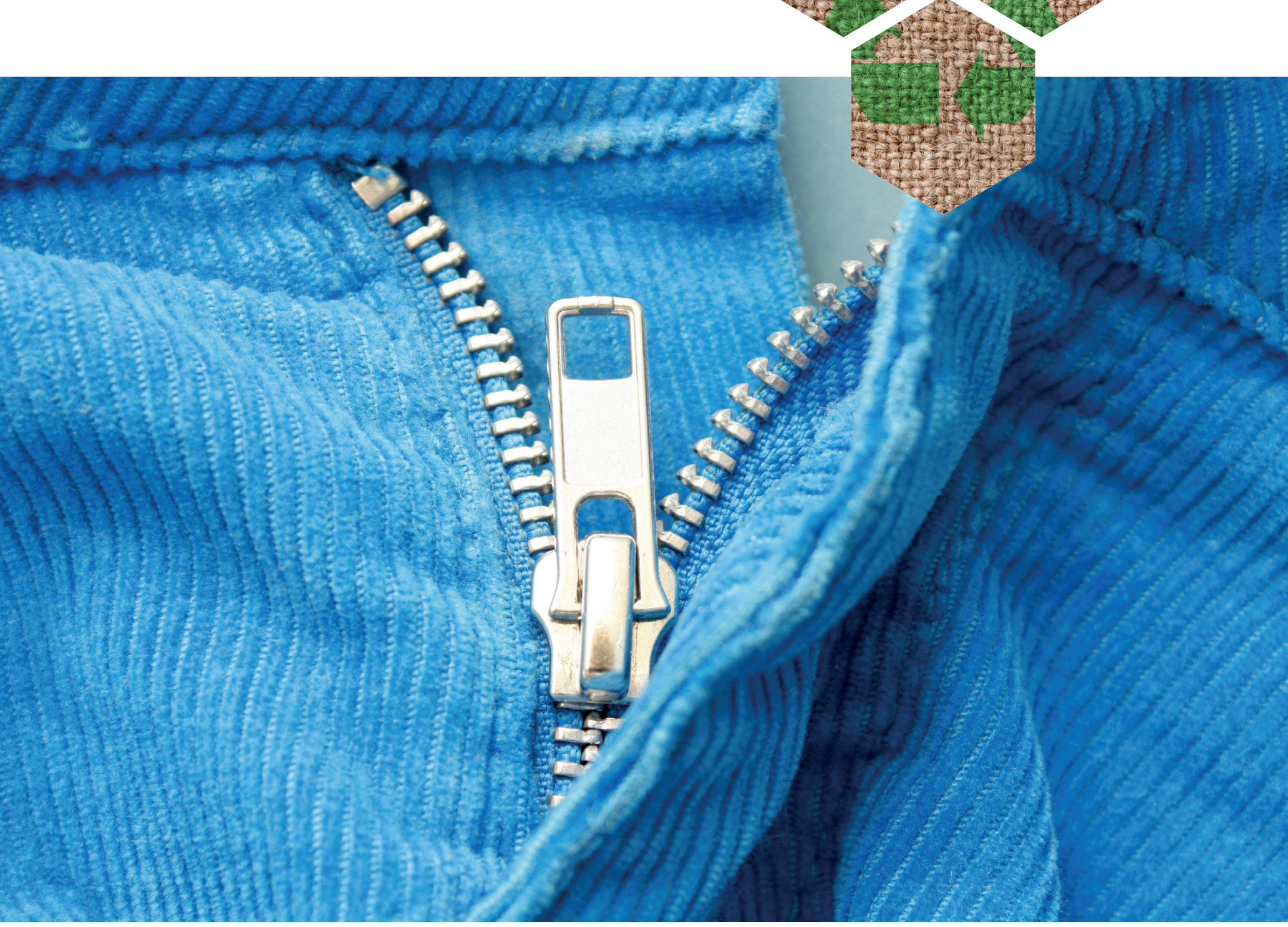


To enable innovative technology to be developed and used in the Nordic region, Nordic policy makers are called to:

\section{- Investigate the need and potentials for an automated sorting facility for used textiles in the Nordic region. To allow for sufficient scale, this should be done on a Nordic level.}

- Support research and development of new technologies for (chemical) textile-to-textile recycling.
A combination of the above

mentioned actions have the potential of creating more than 4,000 jobs, 30,000 work training opportunities while doubling the collection, reuse and recycling of used textiles and textile waste in the Nordic region. In addition to these, policies for increased sustainability in the production of textiles are also called for. 


\section{norden}

Nordic Council of Ministers

Ved Stranden 18

DK-1061 København K

www.norden.org

This policy brief on Nordic textile reuse and recycling is part of the Nordic Prime Ministers' overall green growth initiative, The Nordic Region - leading in green growth. Read more in the web magazine Green Growth the Nordic Way at www.nordicway.org or at www.norden.org/greengrowth

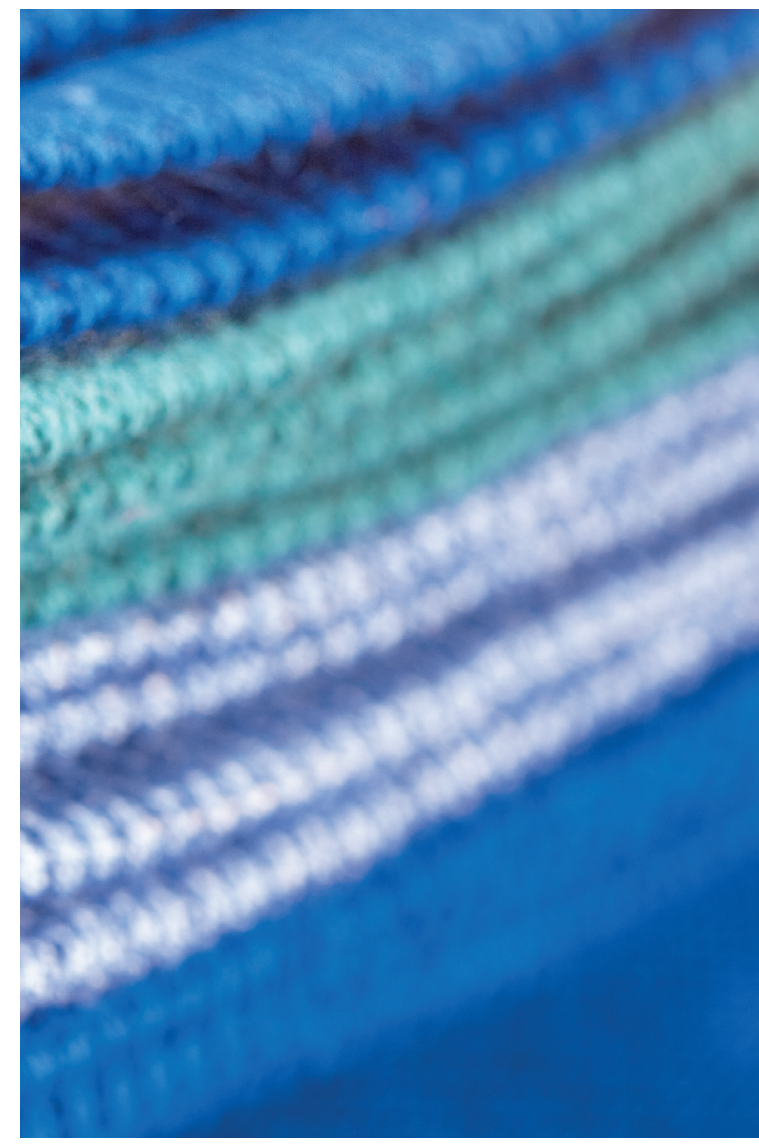

